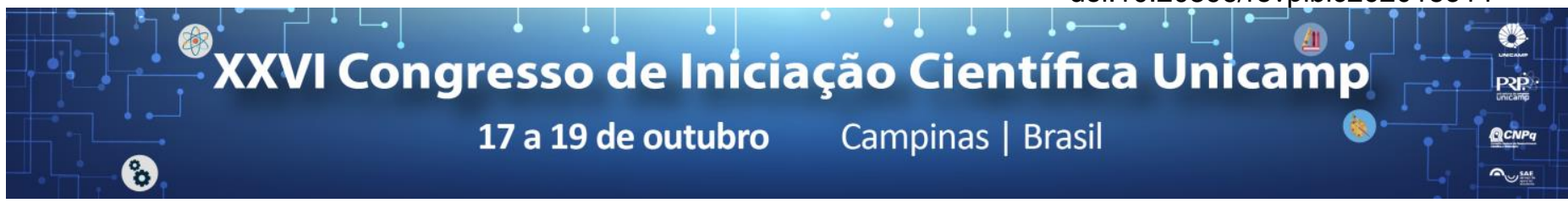

\title{
Influence of disinfection of sanitary effluent on the functional diversity of soil microbial communities
}

\section{Claudio V. Neto*, Lays Leonel Paulino, Jerusa Schneider}

\begin{abstract}
The aim of this project was to evaluate the toxicity and possible alterations of the soil biological environment after the use of disinfected sanitary effluents with peracetic acid, calcium hypochlorite and UV radiation. For this, phytotoxicity tests were performed with sunflower and castor bean seeds. The analysis of the alteration of the microbial community was carried out through the use of Biolog microplates. It was concluded that peracetic acid and calcium hypochlorite did not alter the soil microbiota, being indicated as a post-treatment.
\end{abstract}

\section{Key words:}

Treatment of effluents, disinfection, soil microbiome.

\section{Introduction}

A major consumer of available water on the planet is agriculture; an estimated $83 \%$ of its global use is devoted to this activity [1]. Thus, the use of treated sewage appears as a viable alternative to supply the demand of the agricultural sector. However, one of the difficulties found to make safe reuse feasible is to determine an efficient disinfection system for treated sewage that does not generate environmentally harmful by-products [1]. Peracetic acid (AP), calcium hypochlorite (HCa) and UV radiation (UV-LED) are alternatives to chlorinated disinfectants due to the low production of by-products toxic to both the environment and human health.

Therefore, the aims of this work were to determine the toxicity of the sanitary effluent coming from the Wastewater Treatment Plant of Barão Geraldo disinfected with AP, HCa and UV-LED and analyses the alteration of the microbial community by the use of disinfected effluent in the soil.

\section{Results and Discussion}

We tested several concentrations and exposure times with the effluent from the Wastewater Treatment Plant of Barão Geraldo district, Campinas (SP), linked to a PhD project of the Faculty of Civil Engineering, Architecture and Urbanism of UNICAMP. With the results obtained from the dosage and optimum contact times of each disinfectant agent, we carried out phytotoxicity tests on sunflower seeds (Helianthus annuus L.) and castor beans (Ricinus communis L.). The evaluation of the alteration of the microbial community by the use of disinfected effluent in the soil, followed the standards proposed by Li et al. [2], being evaluated for ten days.

The Table 1 shows that both treatments showed no toxicity in any experiment. However, looking the possibility of alteration in the microbiological community due to the use of the disinfected effluent in the soil, it noticed that the application of the raw effluent without disinfection promoted high ecotoxicity. On the other hand, disinfection with $\mathrm{HCa}$ and $\mathrm{AP}$ showed low ecotoxicity (Figure 1).
Table 1. Germination and root growth of sunflower seed and castor bean disinfected sanitary effluents with peracetic acid, calcium hypochlorite and UV-LED radiation (mean \pm standard deviation; $n=4)$.

\begin{tabular}{|c|c|c|c|c|}
\hline \multicolumn{5}{|c|}{ Sunflower (Helianthus annuus L.) } \\
\hline & UV-LED & $\mathrm{HCa}$ & AP & BR \\
\hline Germination (\%) & $50 \pm 11,6$ & $\begin{array}{c}57,5 \pm \\
17,1\end{array}$ & $\begin{array}{l}50 \pm \\
14,1\end{array}$ & $\begin{array}{l}45 \pm \\
26,5\end{array}$ \\
\hline $\begin{array}{l}\text { Root Growth } \\
\text { (cm) }\end{array}$ & $6 \pm 4$ & $8 \pm 6$ & $5 \pm 3$ & $8 \pm 6$ \\
\hline \multicolumn{5}{|c|}{ Castor (Ricinus communis L.) } \\
\hline & UV-LED & $\mathrm{HCa}$ & AP & BR \\
\hline Germination (\%) & $47,5 \pm 9,6$ & $\begin{array}{c}37,5 \pm \\
9,6\end{array}$ & $\begin{array}{c}37,5 \pm \\
17,1\end{array}$ & $\begin{array}{l}45 \pm \\
26,5\end{array}$ \\
\hline $\begin{array}{l}\text { Root Growth } \\
\text { (cm) }\end{array}$ & $2 \pm 1$ & $2 \pm 2$ & $1 \pm 1$ & $2 \pm 1$ \\
\hline
\end{tabular}

UV-LED: radiation UV-LED with 15 minutes; $\mathrm{HCa}$ : Calcium hypochlorite $(40 \mathrm{mg} / \mathrm{L})$; AP: Peraceti Acid (40 mg/L); BR - Soil with tap water application

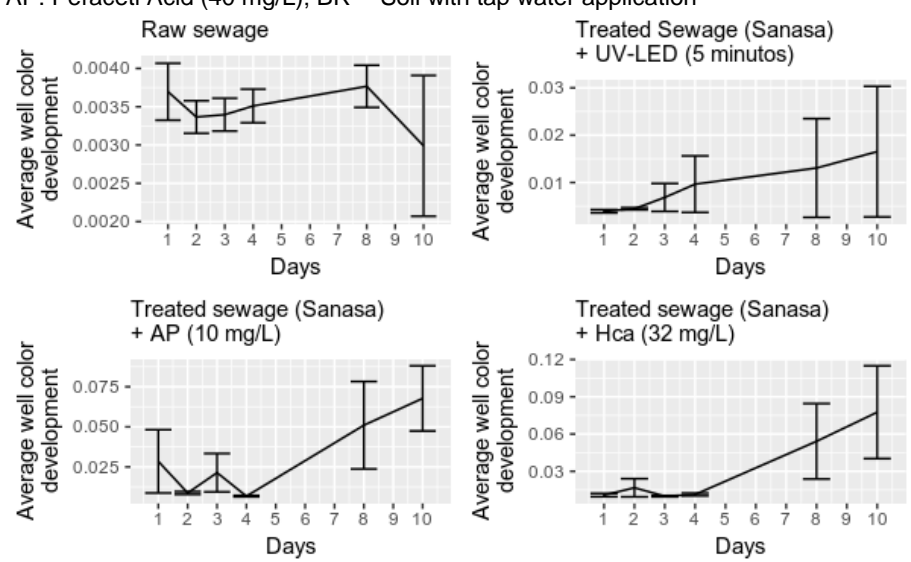

Figure 1. Average well color development (AWCD) to effluents apply at soil.

\section{Conclusions}

Disinfection with $\mathrm{HCa}$ and AP not caused toxic effects, it did not alter the soil microbial environment, and therefore they are a form of post-treatment under these conditions. 